\title{
Entrevista com Naomar de Almeida Filho, por Paulo Amarante
}

Interview with Naomar de Almeida Filho, by Paulo Amarante

Tomando como ponto de partida que a saúde mental é elemento constitutivo do amplo campo da saúde pública, buscou-se através desta entrevista, com um dos mais importantes representantes da epidemiologia psiquiátrica, a partir de sua própria experiência, apresentar uma análise desse campo. Este relato biográfico revela um percurso não incomum entre os profissionais da saúde coletiva que é o de sintetizar no seu acervo de conhecimento as contribuições de diversas disciplinas. Infelizmente por limitação de espaço na revista, a longa entrevista com o autor teve que ser resumida, não perdendo, no entanto, a riqueza de seu conteúdo.
Amarante Como foi sua escolha pela medicina? E na medicina, por que psiquiatria? Almeida Filho Na época, quem se achava com vocação para exatas fazia engenharia, quem se interessava por literatura ou humanidades fazia direito, e quem gostava de ciências naturais fazia vestibular para medicina. Como a maioria dos estudantes de medicina da minha geração, passei os primeiros meses do curso decidido a me tornar cirurgião. Dois períodos de férias no interior, cumprindo estágios informais em hospitais e clínicas, rapidamente me fizeram mudar de idéia, cursei com interesse a disciplina psicologia médica e psicopatologia. Participei de um seminário sobre Psiquiatria Transcultural, promovido pelo Departamento de Neuropsiquiatria da Faculdade de Medicina da UFBA, na antiga sede do Terreiro de Jesus. Recordo com clareza, no entanto, uma palestra de Vivaldo da Costa Lima, sobre a contribuição da antropologia para a psiquiatria, citando os nomes de Lévi-Strauss e Roger Bastide, que me despertaram imediata curiosidade. Cursei o estágio rotativo de psiquiatria, participando de um grupo de estudos sobre psicanálise, onde estudamos metodicamente o Projeto de uma Psicologia Científica (para Neurólogos), importante texto básico de Freud. No final de uma sessão científica organizada pelo Departamento de Neuropsiquiatria, o professor Rubim me apresentou como se 
eu fosse um dileto discípulo (o que naquela época seria tão somente uma gentileza já que os docentes sequer sabiam o meu nome). Devo ter balbuciado algo sobre tornar-me um pesquisador na área da psiquiatria cultural, porque o Herr professor indagou sobre meus planos de carreira e convidou-me a prosseguir estudos de pós-graduação no seu departamento. Na semana seguinte, matriculei-me no Instituto Goethe e comecei a estudar Kraepelin e Jaspers a sério.

Foi nessa época que comecei a revisar mais sistematicamente temas de psiquiatria social, participando de um grupo de estudos coordenado por Luiz Umberto Pinheiro, recém-chegado de uma especialização em epidemiologia psiquiátrica na Universidade de Londres. Estudávamos textos de Scheff, Szasz, Dunham, Caplan, Wing, Cooper, Dohrenwend, Susser, entre outros, através de fotocópias oriundas de uma pequena biblioteca organizada como preparação para um programa de saúde mental que se estava planejando no recém-inaugurado Centro Comunitário Mário Leal, sob a direção de Domingos Coutinho.

Amarante Quando, como e por que você optou depois pela saúde coletiva e, nela, pela epidemiologia?

Almeida Filho Já finalizava o internato e planejava dedicar-me à carreira clínica, identificando a psiquiatria infantil como subárea de escolha. Face à interdição de cunho políticotrabalhista, que me impedia de iniciar carreira na psiquiatria clínica, fiz a seleção para o mestrado em saúde comunitária da UFBA onde, sob orientação do professor Jairnilson Paim, pude dirigir minha formação para uma carreira docente e de pesquisa. Portanto, fui compelido a desistir da carreira clínica e felizmente, como muitos sanitaristas brasileiros, terminei em um doce exílio no campo da saúde coletiva.

Amarante O movimento da Renovação Médica iniciado na psiquiatria baiana, do qual você foi um dos principais protagonistas, representou um marco importante no âmbito das políticas públicas em saúde mental. O que representou para você esse movimento? Como você o interpretaria atualmente, passados 24 anos?

Almeida Filho Foi realmente fundamental para minha formação pessoal e profissional como pesquisador. Em 1976, participando da reorganização da Associação Psiquiátrica da Bahia e do embrião do movimento de Renovação Médica (que seria depois muito importante na luta pela abertura política do país), interessava-me bastante pelas questões sociais e políticas da área da saúde mental. A minha entrada na área da psiquiatria social deu-se através do Programa de Saúde Mental do Mestrado em Saúde Comunitária. O programa tinha um duplo objetivo: por um lado, pretendia testar um projeto piloto de saúde mental comunitária em um bairro de baixa renda de Salvador; por outro lado, cultivava a ambição de influir no desenho de um sistema regional de assistência psiquiátrica mais humano e democrático.

Estudávamos os principais autores que subsidiavam uma perspectiva de crítica política da saúde mental no mundo contemporâneo, desde os teóricos do estruturalismo marxista, como Louis Althusser e Nicos Poulantzas, aos proponentes de um pensamento crítico da psiquiatria, como os antipsiquiatras Laing, Cooper e Thomas Szazs e, com um respeito todo especial, Michel Foucault e Franco Basaglia. A visita de Michel Foucault à Bahia em 1976 foi por nós especialmente festejada. Na conferência, Foucault insistiu sobre a importância de se estudar a cotidianidade e o que chamava de micro-poderes.

Infelizmente para mim, quando Franco Basaglia visitou Salvador em 1978 encontravame nos Estados Unidos, cumprindo programa de doutoramento. Não obstante, devo ter desempenhado um pequeno papel na difusão do pensamento de Basaglia entre os ianques.

Em 1979, cursando um Programa de Verão em Antropologia Médica em Taos, Novo México, tive a oportunidade de conviver, em pessoa, com algumas referências bibliográficas que habitavam as minhas leituras da época, como Thomas Scheff, Robert Edgerton, George DeVos, sob a direção de Nancy Scheper-Hughes.

Amarante Você certamente acompanha o processo brasileiro de transformações no campo da saúde mental, denominado por uns de Reforma Psiquiátrica, por outros de Luta Antimanicomial, dentre outras denominações ainda. Como você percebe esse processo? Almeida Filho São questões muito complexas, que excedem a minha capacidade de respondê-las É difícil para mim hoje avaliar positivamente os avanços da luta política psi- 
quiátrica. Vejo mais uma letargia e um quase escamoteamento do problema da saúde mental, como se a esquerda estivesse tratando os problemas emocionais dos sujeitos como um luxo ou um supérfluo a ser desprezado, secundarizado pela pobreza, pelo desemprego e pela exclusão social dos nossos dias. Creio que é preciso trazer de volta a problemática da saúde mental à cena frontal da sociedade brasileira, e para isso a epidemiologia, sem dúvida, constitui um importante instrumento.

Amarante A psiquiatria epidemiológica brasileira deve muito à sua contribuição. Como você caracterizaria esta contribuição?

Almeida Filho Minha carreira de pesquisador na área da saúde mental pode ser desdobrada em duas linhas de trabalho: epidemiologia psiquiátrica infantil e neuropsicoepidemiologia de adultos.

No momento em que me iniciava como pesquisador, poucas investigações epidemiológicas sobre doenças mentais na infância e adolescência haviam sido realizadas em todo o mundo. Por esse motivo, fui praticamente forçado a criar uma metodologia própria. Assim, projetei uma técnica modular de identificação de casos psiquiátricos infantis para estudos epidemiológicos. Desenhei um instrumento de screening que veio a se chamar QMPI (Questionário de Morbidade Psiquiátrica Infantil), com base na classificação triaxial de transtornos mentais em crianças, proposta por Rutter e colaboradores (1969).

Em seguimento a esse desenvolvimento metodológico, tive a rara oportunidade de conduzir o primeiro estudo de morbidade psiquiátrica infantil na América Latina publicado em 1985, Epidemiologia das desordens mentais na infância no Brasil.

Em 1987, participei de um importante estudo sobre as relações entre fatores socioeconômicos, ambiente familiar precoce e saúde mental infantil numa outra área de baixa renda de Salvador, como resultado de um estágio no Departamento de Pesquisas do Centre Médical Marmottan, em Paris, sob a direção de Claude Olievenstein. Decidi investir no desenvolvimento da pesquisa epidemiológica sobre toxicomanias em adolescentes, em colaboração com Vilma Santana e Antônio Nery Filho (diretor do CETAD - Centro de Estudos e Terapia do Abuso de Drogas). Desta experiência destacaria dois estudos: uma revisão sistemática de pesquisas publicadas no International
Journal of the Addictions e um inquérito domiciliar sobre consumo de drogas (único publicado no Brasil, até esta data).

A minha primeira experiência de investigação epidemiológica em comunidade foi o pioneiro estudo conduzido por Domingos Coutinho, em 1974, que possibilitou a consolidação posterior de uma linha de pesquisa em torno da epidemiologia de transtornos neuropsiquiátricos de adultos.

Esse estudo, planejado e coordenado por Vilma Santana no seu segmento de saúde mental em adultos e por mim no que se refere a morbidade psiquiátrica infantil, introduziu uma técnica inovadora de amostragem, empregando áreas e núcleos familiares como unidades amostrais, que se tornou amplamente utilizada nos levantamentos brasileiros, por sua aplicação fácil e rápida em localidades de urbanização precária.

Focalizei a hipótese de que indivíduos excluídos do sistema de produção (pertencentes ao exército industrial de reserva) apresentariam níveis de sintomatologia psiquiátrica mais elevados do que aqueles inseridos no mercado formal de trabalho. A associação positiva verificada para os dados brutos foi mantida após a análise de covariância, não refutando, consequentemente, a hipótese sob teste. Esses dados me levaram a concluir que o processo de migração e os fenômenos socioculturais a ele associados (aculturação, mudança de vida, mudança cultural até) não estariam implicados na determinação da doença mental, no contexto estudado.

Em 1982, publiquei em colaboração com Sérgio Bastos, o primeiro estudo tipo caso-controle em psiquiatria realizado no Brasil (também pioneiro, creio, na América Latina). Nessa pesquisa, testamos a hipótese de associação entre migração e transtornos depressivos em mulheres, e encontramos um odds ratio de 5,93, estatisticamente significante mesmo após o controle simultâneo das variáveis de confundimento incluídas na análise. Empreendi em 1982, em colaboração com Rubim de Pinho e Vilma Santana, uma re-análise dos dados do Estudo de O, resultando em uma investigação pioneira sobre a morbidade neuropsiquiátrica em idosos.

Em 1983, tive a oportunidade de planejar e conduzir outra investigação de morbidade psiquiátrica baseada em comunidades, no contexto de um estudo mais amplo das relações entre desenvolvimento econômico e situação 
de saúde, efetuado numa área industrial da Região Metropolitana de Salvador. Em 1984, participei de um estudo pioneiro de prevalência de transtornos mentais em população rural. Do meu conhecimento, este ainda é o único estudo epidemiológico de morbidade mental realizado em área rural no país.

A tecnologia de construção e testagem de instrumentos padronizados para o diagnóstico de condições psiquiátricas específicas, especialmente aplicáveis em estudos epidemiológicos populacionais, por mim desenvolvida na fase inicial dedicada à neuropsiquiaria infantil, foi posteriormente replicada em relação a outras questões de pesquisa. Assim, entre 1986 e 1988, coordenei o processo de criação e validação da Escala para Detecção de Alcoolismo e Sintomatologia Associada/EDASA, bem como de uma metodologia para a condução de estudos epidemiológicos sobre o consumo de drogas ilícitas em escolares. Participei ativamente da re-testagem e avaliação da estrutura fatorial do QMPA, e colaborei com a primeira avaliação de desempenho do SRQ-20 em população profissional no Brasil.

Em 1990, por encomenda da Coordenação de Saúde Mental do Ministério da Saúde, buscando suprir a carência de dados epidemiológicos necessários para a implementação da assistência à saúde mental no país, planejamos um levantamento de larga escala da morbidade neuropsiquiátrica na população de seis regiões metropolitanas brasileiras.

Pioneira na América Latina no que se refere ao uso de estratégias estruturadas de avaliação diagnosticada em desenhos de cortetransversal, esta pesquisa consolida cada vez mais a investigação na área da epidemiologia psiquiátrica no Brasil.

Amarante Você introduziu a "epidemiologia sem números". Fale mais sobre ela.

Almeida Filho Você se refere à minha segunda área temática: a investigação epistemológica do campo epidemiológico.

Em 1983, Carlos Marcílio de Souza, coordenador de Saúde e Nutrição do CNPq, convidou-me para uma consultoria junto ao Programa de Epidemiologia, na época ainda em fase de proposta preliminar. Dessa iniciativa resultou um texto de trabalho sobre as bases históricas e metodológicas da epidemiologia que foi o embrião de uma série de ensaios que escrevi entre 1984 e 1988, revisados e reunidos em um pequeno volume intitulado Epidemio- logia sem números, posteriormente traduzido para o castelhano e publicado pela Organização Pan-Americana da Saúde, que se encarregou de difundi-lo mais ainda no âmbito latino-americano. Não resulta fácil especificar, tal como na epidemiologia psiquiátrica, os elementos de inovação introduzidos pela minha atuação nesta área temática.

Inicialmente, sistematizei uma proposta de adoção do "pluralismo nômico" de Bunge, articulada a uma perspectiva provisoriamente popperiana, na pesquisa epidemiológica. Com base nessa perspectiva, desenvolvi uma tipologia triaxial dos desenhos de estudo em epidemiologia, fundamentado nos critérios de unidade de observação-análise, posicionamento do investigador e temporalidade do estudo.

No final dos anos 80, formalizei o problema do objeto de conhecimento na disciplina, através de uma aproximação "praxiológica", analisando criticamente as abordagens convencionalista e estruturalista então vigentes. Reavaliei criticamente a categoria "causa", identificando as suas metáforas fundamentais (evento, nexo e fluxo) e as perspectivas futuras dessa categoria no campo epidemiológico, busquei estabelecer um posicionamento pragmático perante o problema da cientificidade em geral, que denominei de "relativismo atenuado", privilegiando uma orientação pragmática e evitando o caráter anunciatório e prescritivo das propostas de abertura paradigmática.

Desenvolvi uma crítica da epidemiologia social latino-americana, apontando o monodeterminismo, o estruturalismo e a epistemologia objetivista como questões problemáticas das suas principais vertentes. Aproveitando um período como professor visitante na Universidade de Montréal, participei do desenvolvimento epistemológico-teórico da Teoria dos S/Smp (Systems of signs, meanings and practices), juntamente com Gilles Bibeau e Ellen Corin. Propus, de modo sistemático e analítico (creio que também pioneiramente), a incorporação da abordagem da complexidade na pesquisa epidemiológica, em direção a um novo paradigma científico no campo da epidemiologia.

Finalmente, penso ter identificado uma importante (e inesperada) lacuna teórica na epidemiologia: a ausência de uma teoria da saúde. E é nisso que estou trabalhando atualmente.

Amarante Como esse interesse por uma epistemologia da epidemiologia evoluiu e como se reflete no campo da saúde mental? 
Almeida Filho Durante o curso de mestrado, na segunda metade da década de 1970, participava de um grande esforço de apropriação teórica na área da saúde. Nessa época, já desconfiava que o principal problema da epidemiologia, que tem inscrito o "social" em seu próprio nome, seria justamente sua dificuldade em abordar o social.

Dada a perspectiva de continuar a minha formação pós-graduada, a Universidade da Carolina do Norte acolheu-me como aluno do programa de doutorado, indicando Berton Kaplan como orientador porque John Cassei acabara de falecer naquele ano.

Minha primeira opção no curso de teorias sociais em saúde nos obrigou a passar um semestre inteiro estudando The Social System e The Theory of Social Action, livros sagrados do estrutural-funcionalismo, o que posteriormente me fez jamais subestimar a sofisticação e complexidade do pensamento sociológico anglo-saxão, de certa forma imunizando-me contra o maniqueísmo.

A contribuição do grupo de escolas sociológicas chamadas funcionalistas, às quais de algum modo se filiava o grupo de Chapel Hill, expressava-se melhor em um conjunto de hipóteses que, com certa liberdade, se poderia chamar de teoria, sobre as conseqüências para a saúde do processo social fundamental (no seu ponto de vista) por que passavam as sociedades ocidentais contemporâneas, o processo de modernização, fonte primária de estresse social e cultural. Aprendi com alguns dos construtores dessa teoria que os agentes estressantes operam indiretamente (ou condicionalmente) em virtude de sua capacidade de atuar na esfera simbólica. Os estressores podem ser de natureza individual, com ação aguda, equivalentes ao que se designou como "crises vitais" ou "eventos de vida" sob a forma de tensão crônica, ou de natureza coletiva; igualmente com ação aguda, como as guerras e os desastres naturais, e com ação crônica, o chamado "estresse social" da opressão, da miséria e das desigualdades sociais.

Tendo a teoria do estresse como ilustração, compreendi que a abordagem funcionalista não era tão simplificadora e ingênua quanto as nossas leituras latino-americanas engajadas nos faziam crer.

$\mathrm{Na}$ minha tese de doutoramento busquei demonstrar como essa concepção representa uma abordagem extremamente ideologizada dos contextos sociais chamados tradicionais, como se fossem blocos homogêneos, na medida que seriam supostamente formados por indivíduos que compartilhavam formas culturais e objetivos sociais em comum. Não obstante, ambicionava realizar uma recuperação dessas contribuições aparentemente antagônicas através da sua articulação ao marco teórico histórico-estrutural.

Com relação à teoria do estresse, perseguiase uma especificação das bases epistemológicas formais de tais modelos teóricos, com a pretensão de construir o novo marco referencial por meio da negação construtiva dos elementos fundamentais da velha teoria, examinando-se a formulação de uma série de oposições conceituais elementares: coletivo versus individual, específico versus geral, concreto versus abstrato.

Tentei um caminho diferente, resultando em uma linha de pesquisa empírica que se poderia designar como "psicoepidemiológica". Hoje posso avaliar que as dificuldades da articulação pretendida entre a "teoria do estresse" e a "teoria da exclusão social" certamente ajudaram a consolidar o meu investimento posterior nas questões epistemológicas fundamentais da epidemiologia.

Amarante Existe uma escola baiana de epidemiologia? Como poderia a produção brasileira no campo da epidemiologia ser caracterizada no cenário internacional? Existe uma efetiva contribuição brasileira neste campo?

Almeida Filho Em minha opinião, é precoce falar de uma Escola Epidemiológica Baiana no mesmo sentido com que se refere à Escola Tropicalista Baiana. Temos efetivamente alguns pesquisadores produtivos em vários campos de investigação epidemiológica. Com relação à segunda parte da pergunta, sou inteiramente cético quanto a uma potencial influência da epidemiologia brasileira no cenário internacional. Menos por debilidades da nossa produção científica epidemiológica e mais por uma certa refratariedade do main-stream da epidemiologia frente às questões que mobilizam os pesquisadores nacionais. Realmente, pouco tem interessado à massa de epidemiológos anglo-saxões os temas, apaixonantes para "nosotros" latino-americanos - da filosofia, da história e da política na epidemiologia.

No tempo da minha formação, tínhamos um programa de saúde mental bastante bemdiferenciado das outras linhas de pesquisa do antigo Departamento de Medicina Preventiva. 
Com a implantação do Instituto de Saúde Coletiva, que tem como um dos seus princípios básicos a transdisciplinaridade, deixou de fazer sentido compartimentalizar a saúde mental. Assim é que temos formação em nível de pós-graduação e pesquisa sobre temas de saúde mental em várias das suas interfaces e nunca em isolamento. Vilma Santana estuda a relação entre saúde mental e trabalho em mulheres e em grupos especiais da população; Darci Neves investiga as interações entre doenças infecciosas e desenvolvimento emocional de crianças; Ana Cecília Bastos e Leni Trad desenvolvem projetos sobre a saúde mental da família tendo como foco as práticas de saúde; Carlos Cardoso coordena um projeto etnoepidemiológico sobre os signos, significados e práticas de saúde mental na comunidade. Eu tenho a sorte e o privilégio de poder interagir com todos esses grupos de pesquisa, contribuindo no que posso para o desenvolvimento metodológico dos diversos projetos. 